\title{
P I 5-25. Preparation for HIV vaccine trials in Africa: barriers and facilitators for the establishment of a community advisory board in Burkina Faso
}

\author{
A Berthe ${ }^{1}$, N Meda ${ }^{2}$, IT Traoré*2, J Some ${ }^{2}$, S Salouka1 ${ }^{1}$ L Sanou1 ${ }^{1}$, F Some², \\ J Rouamba1 ${ }^{1}$, D Ouedraogo ${ }^{2}$, G M'Boutiki ${ }^{2}$, P Mayaud ${ }^{3}, \mathrm{~N} \mathrm{Nagot}^{4}$ and P Van \\ de perre ${ }^{4}$
}

Address: ${ }^{1}$ Centre MURAZ, Bobo-Dioulasso, Burkina Faso, ${ }^{2}$ Projet Vaccin VIH, Site ANRS-UFR/SDS Université de Ouagadougou, Ouagadougou, Burkina Faso, ${ }^{3}$ Clinical Research Unit, London School of Hygiene \& Tropical Medicine, London, UK and ${ }^{4}$ Université Montpellier 1, EA 4205, Montpellier, France

* Corresponding author

from AIDS Vaccine 2009

Paris, France. 19-22 October 2009

Published: 22 October 2009

Retrovirology 2009, 6(Suppl 3):P226 doi:10.1 I86/1742-4690-6-S3-P226

This abstract is available from: http://www.retrovirology.com/content/6/S3/P226

(C) 2009 Berthe et al; licensee BioMed Central Ltd.

\section{Background}

Involvement of community level stakeholders in the future HIV vaccine trials is essential to ensure that rights, views, concerns, needs and expectations of the target population are fully taken into account in all phases of their implementation. We carried out a multicomponent situation analysis in two future urban sites in Burkina Faso to identify the proper way to setting up a $\mathrm{CAB}$ competent to accompany the trials.

\section{Methods}

HIVTAB project is funded by European and Developing Countries Clinical Trials Partnership in Tanzania and partly by French National Agency for AIDS Research (ANRS) in Burkina Faso to strengthen research capacities in preparation to future HIV vaccine trials. Social science methods were applied in recruiting of 23 key informants for in-depth interviews and 03 focus groups discussions between investigators and representatives of communitybased NGOs were conducted.

\section{Results}

Since 2007 Sidaction provided support to a Network of NGO'S involved in protection of research participants. Also ANRS supports clinical trials in Burkina properly shaped by ANRS ethics charter. The community's leaders want the New CAB to be built around Sidaction initiative. They also prefer one CAB for all the research projects fully or partly managed by the ANRS in Burkina Faso. This CAB will provide impartial witnesses and advice on research design, implementation and dissemination of findings to the community. To protect the confidentiality of studies participants, all members of CAB will sign a confidentiality agreement. The community's representatives want to charge all the projects, particularly the HIVTAB-Project for all the fees related to the implementation of the CAB.

\section{Conclusion}

The EDCTP-funded HIVTAB project, by establishing a $\mathrm{CAB}$ will enhance community involvement in preparation for future HIV vaccine trials. Nevertheless the funding sources of this $\mathrm{CAB}$ and the qualification of community representatives need further discussions and clarifications to not jeopardize its independence and credibility. 